The Eurasian Seismic Activity

\title{
Seismic Risk of Modern City
}

\author{
Vladislav Zaalishvili $^{1,2}$, Olga Burdzieva ${ }^{1}$, Aleksandr Kanukov $^{1,2}$, Dmitry Melkov $^{1,2}$, Boris Dzeranov ${ }^{1,2}$ \\ ${ }^{1}$ Geophysical Institute, Vladikavkaz Scientific Center, Russian Academy of Sciences, 362002, \\ Vladikavkaz, Russia \\ ${ }^{2}$ North-Ossetian State University after K.L. Khetagurov, 362025, Vladikavkaz, Russia
}

doi: https://doi.org/10.21467/abstracts.93.49

\section{ABS T RA C T}

Introduction. The Republic of North Ossetia-Alania is located in a seismically active zone. It seems natural to estimate the seismic risk in Vladikavkaz - the capital of the Republic (Sobolev et al., 1997; Zaalishvili et al., 2018). Kuybyshev Street and the adjacent neighborhoods were selected for the study. The following factors determined the choice of this region as the object of study: a relatively large area of the region (1.35 $\mathrm{km}^{2}$ ); objects of various types of structures with different number of storeys (houses, schools, administrative and public buildings, markets, etc.) are situated within this territory; the area under study includes almost all soil conditions characteristic of the entire territory of Vladikavkaz.

Calculation of the expected economic losses. Distribution of economic losses during an intensity 8 earthquake is shown in Fig. 1, which clearly shows that the largest economic losses should be expected in areas 2 and 3, which, first of all, is due to soil conditions. At the same time, the risk of economic losses for site 1 ("Vesna" micro-district) is insignificant, due to the fact that the development of this area consists entirely of D-type buildings (Zaalishvili et al., 2001). At the same time, considering possible tilting of buildings caused by soil liquefaction, an economic risk will increase several times and according to our assessments will be about 400 million rubles (damage to about 30\% of building stock) Fig. 1.

\section{Economic losses in the case of 8 points earthquake}

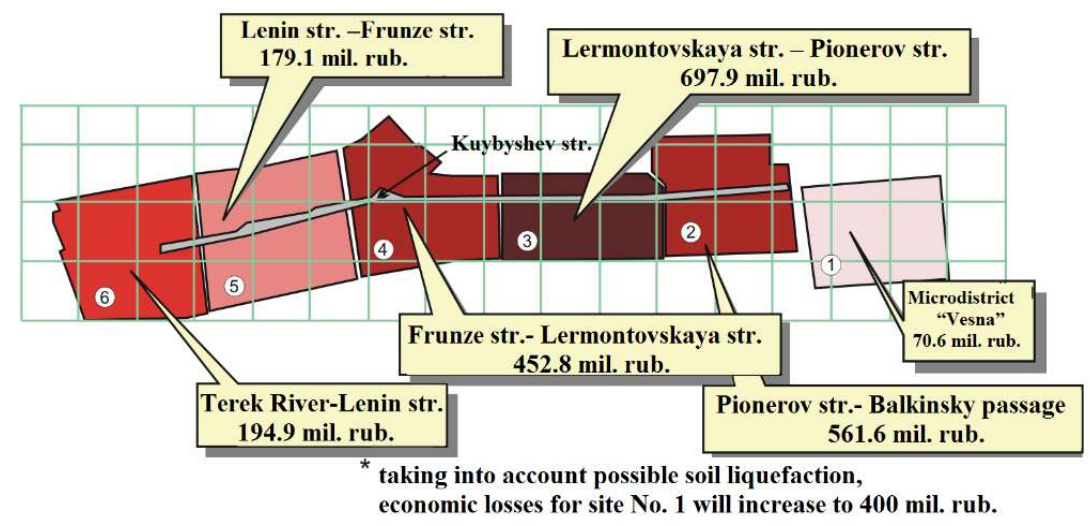

Figure 1. Expected economic losses in the case of 8 points earthquake for Vladikavkaz (for average soil conditions)

Calculation of social losses in the vicinity of Kuybyshev Street for earthquakes of varying intensity. Using the expected damage percentages by damage rate and the corresponding damage rate values for different intensity levels on the MSK-64 scale, the number of buildings and structures (a majority, individual, average) of different levels, the expected social losses of the population were calculated - Fig. 2. These data are undoubtedly average and, unfortunately, can be significantly exceeded in a case of poor-quality

(C) 2020 Copyright held by the author(s). Published by AIJR Publisher in "Abstracts of The Second Eurasian RISK-2020 Conference and Symposium” April 12- 19, 2020, Tbilisi, Georgia. Jointly organized by AMIR Technical Services LLC, Georgian Technical University, Institute of Geography (Kazakhstan) and Russian Institute of Petroleum Geology and Geophysics.

DOI: $10.21467 /$ abstracts. 93 
The Second Eurasian RISK-2020 Conference and Symposium

construction. Everywhere in our calculations, it is assumed that the quality of work complies with the standards (at least for the construction period). (Mitigating, 1991) Considering that the main part of the already existing development is characterized by a seismic resistance deficit of 1-2 points and sometimes more, very important attention should be paid to the quality of work (Zaalishvili et al., 2016). In particular, it is also necessary to take into account depreciation rates of buildings and structures.

\section{Social losses in the case of 8 points earthquake}

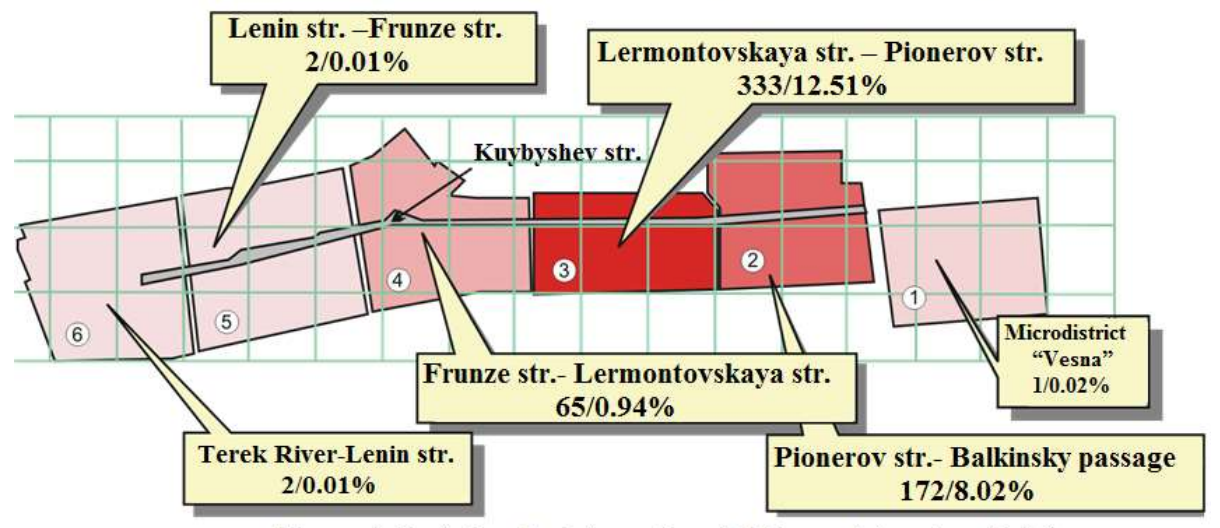

Figures indicate the absolute number of victims and / number of victims as a percentage of the population of the site.

Figure 2. The expected social losses in the case of 8 points earthquake for Vladikavkaz (for average soil conditions)

\section{Conclusions}

Seismic risk assessment of a modern city on the example of a test area of the Vladikavkaz city is considered. Developed methodology is based on simple and effective statistical concepts of MSK-64 scale. Risks of economical and social losses are ultimately different depending on site conditions and building type, for example social risk of "Vesna" region is minimal due to a modern building type solution, while economic risk is height due to liquefaction phenomenon. So seismic risk methodology was corrected for new types of buildings and it was shown that MSK scale is effective but must be also actualized itself. The suggested methodology gives rapid express assessment of seismic risk for decision making on buildings enforcement on a city level.

\section{References}

Mitigating Natural Disaster: Phenomena, Effects and Options. A Manual for Policy Makers and Planners. U N D R O. United Nations, N ew York, 1991. $164 \mathrm{p}$

Sobolev G.A. Seismic hazard and seismic risk assessment. Manual for officials. Institute of Seismology, RAS Institute of Seismology. M. IPE RAS, 1997. - 26 p. (in Russ.)

Zaalishvili V.B., Chachava N.T., Gogmachadze S.A. Seismic risk assessment methods in old Tbilisi. Natural Disasters designing for safety. Proceedings of UIA work programmed conference. UIA-Chamber of Architects of Turkey. - Istanbul. 2001, pp. 81-88.

Zaalishvili, V. B.; Melkov, D. A.; Kanukov, A. S., et al. Application of microseismic and calculational techniques in engineering-geological zonation. International Journal of Geomate. 2016, Vol. 10, Issue 19, pp. 1670-1674

Zaalishvili, V. B.; Melkov, D. A.; Dzeranov, B., V., et al. Integrated instrumental monitoring of hazardous geological processes under the Kazbek volcanic center. International Journal of Geomate. 2018, Vol. 15, Issue 47, pp. 158-163 